\title{
Meteor Crater formed by low-velocity impact
}

\section{The paucity of melted rock in this crater may be due to the striking projectile's speed.}

$\mathrm{M}$

eteor Crater in Arizona was the first terrestrial structure to be widely recognized as a meteorite impact scar and has probably been more intensively studied than any other impact crater on Earth. We have discovered something surprising about its mode of formation namely that the surface-impact velocity of the iron meteorite that created Meteor Crater was only about $12 \mathrm{~km} \mathrm{~s}^{-1}$. This is close to the $9.4 \mathrm{~km} \mathrm{~s}^{-1}$ minimum originally proposed $^{1}$ but far short of the $15-20 \mathrm{~km} \mathrm{~s}^{-1}$ that has been widely assumed ${ }^{2}$ - a realization that clears up a long-standing puzzle about why the crater does not contain large volumes of rock melted by the impact.

The Earth's atmosphere is an effective but selective screen against small meteoroids: it admits strong, dense iron projectiles before it permits stony objects to penetrate. Large projectiles of both types do penetrate the atmosphere, although they may be fractured by aerodynamic stresses on the way to the surface. Detailed, sophisticated analysis of this process has produced a variety of successful models for the cascade of fragmentation and dispersion of entering projectiles ${ }^{3-6}$.

We applied one of the simpler models ${ }^{4}$ (see supplementaryinformation for methods)

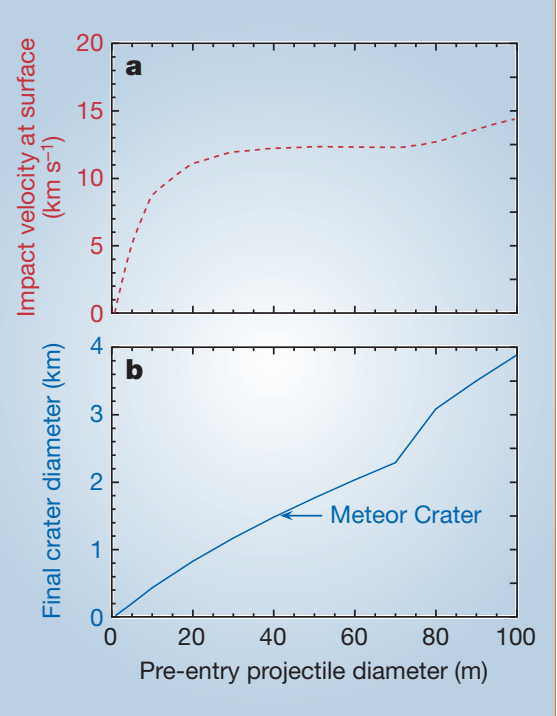

Figure 1 Surface-impact velocity and final crater size as a function of pre-atmospheric projectile size. a, Impact velocity. b, Crater diameter. The pre-atmospheric impact velocity is assumed to be $17 \mathrm{~km} \mathrm{~s}^{-1}$, the angle of approach is $45^{\circ}$ and the iron projectile's density is $8,000 \mathrm{~kg} \mathrm{~m}^{-3}$. Its crushing strength is $50 \mathrm{MPa}$, in agreement with estimates based on observed meteorite falls, such as that of Shikote-Alin ${ }^{5}$. The computations assume a pancake model ${ }^{4}$ with a debris cloud expansion factor of 4 , followed by separation of a fragment that is half the mass of the original projectile, which traverses the final few kilometres as an intact fragment.

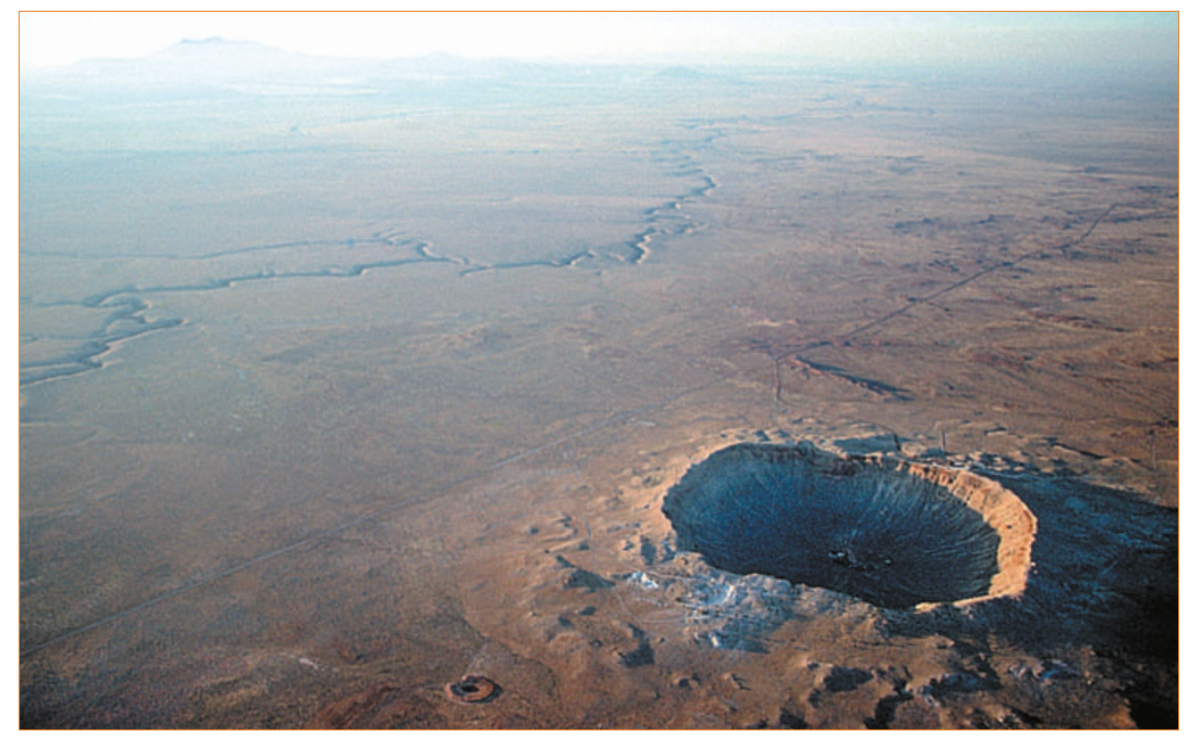

Making an impression: Meteor Crater in Arizona $\left(35^{\circ} 2^{\prime} \mathrm{N}, 111^{\circ} 1^{\prime} \mathrm{W}\right)$ is roughly 1.2 kilometres across.

to Meteor Crater. Our results revealed that the projectile would have been greatly slowed by the atmosphere and would have struck as a dispersed cluster of iron fragments. We conclude that the fragmented iron projectile probably struck the surface at a velocity of about $12 \mathrm{~km} \mathrm{~s}^{-1}$. Figure 1 shows the surface-impact velocity and final crater size for a suite of spherical iron projectiles of up to $100 \mathrm{~m}$ in diameter.

In our scenario, atmospheric drag slows the incoming projectile. As the density of the atmosphere increases, the stagnation pressure reaches 'crushing strength' at an altitude of about $14 \mathrm{~km}$. After the meteor breaks up, the fragments spread out and the drag force on the cluster increases dramatically, resulting in a strong positive feedback. By an altitude of about $5 \mathrm{~km}$, the cluster has expanded to a cloud (shaped like a pancake) of about $200 \mathrm{~m}$ in diameter, with a velocity of $13 \mathrm{~km} \mathrm{~s}^{-1}$. At this point, we assume that a fragment that is one-half the mass of the original projectile separates and continues intact to the surface, where it strikes at $12 \mathrm{~km} \mathrm{~s}^{-1}$, releasing about $2.5 \mathrm{MT}$ (megatonnes of TNT equivalent) of energy. This is a conservative assumption because the aerodynamic stresses are much larger than the crushing strength of iron, and further episodes of crushing and deceleration should occur. The remainder of the projectile's initial energy, about 6.5 MT, is deposited in the atmosphere and initiates a strong airblast.

The surface-impact velocity is too low for substantial melting of the target rock $^{7}$. This result may explain the old observation that there appears to be much less melt in Meteor Crater than would be expected by extrapolation from larger craters ${ }^{8}$. The standard explanation for this discrepancy has been that the porous sedimentary target rocks contained groundwater and this water dispersed the melt into tiny droplets as it vaporized, or that carbonates in the target decomposed explosively to yield carbon dioxide $^{8}$. However, if the consequences of atmospheric entry are properly taken into account, it appears that there is no melt discrepancy at all. Our proposal that Meteor Crater was created by a dispersed swarm of low-velocity iron fragments (many of which were dispersed beyond the central debris cloud) is also consistent with the recovery of large numbers of small, unmelted ironmeteorite fragments near the crater ${ }^{9}$.

\section{H. J. Melosh, G. S. Collins ${ }^{\star}$}

Lunar and Planetary Laboratory, University of

Arizona, Tucson, Arizona 85721, USA

e-mail: jmelosh@lpl.arizona.edu

* Present address: Earth Science and Engineering, Imperial College, London SW7 2AZ, UK

1. Shoemaker, E. M. in The Moon, Meteorites and Comets (eds Middlehurst, B. M. \& Kuiper, G. P.) 301-336 (Univ. Chicago Press, Chicago, 1963).

2. Bryan, J. B., Burton, D. E., Cunningham, M. E. \& Lettis, L. A. in Proceedings of the Ninth Lunar and Planetary Science Conference 3931-3964 (Pergamon, Houston, Texas, 1978).

. Passey, Q. \& Melosh, H. J. Icarus 42, 211-233 (1980).

4. Chyba, C. F., Thomas, P. J. \& Zahnle, K. J. Nature 361, 40-44 (1993)

5. Svetsov, V. V., Nemtchinov, I. V. \& Teterev, A. V. Icarus 116 131-153 (1995).

6. Bland, P. A. \& Artemieva, N. A. Nature 424, 288-291 (2003).

7. Pierazzo, E., Vickery, A. M. \& Melosh, H. J. Icarus 127, 408-432 (1997).

8. Kieffer, S. W. \& Simonds, C. H. Rev. Geophys. Space Phys. 18 143-181 (1980).

9. Nininger, H. H. Arizona's Meteorite Crater (American Meteorite Laboratory, Denver, Colorado, 1956).

Supplementary information accompanies this communication on Nature's website.

Competing financial interests: declared none. 